\title{
ASO Author Reflections: Implementation of Age and Co- morbidity in the Treatment Guideline of Patients with Esophageal Squamous Cell Carcinoma
}

\author{
Z. Faiz, MD, and J. T. M. Plukker, MD, PhD \\ Department of Surgery/Surgical Oncology, University of Groningen, University Medical Center Groningen, Groningen, \\ The Netherlands
}

\section{PAST}

Esophagectomy following neoadjuvant chemoradiotherapy (nCRT) remains standard treatment for patients with potentially curable locally advanced esophageal cancer (EC). In the CROSS study with carboplatin/paclitaxel and $41.4 \mathrm{~Gy} / 23 \times 1.8 \mathrm{~Gy}$, a pathologic complete response was achieved in $23 \%$ and $49 \%$ of patients with esophageal adenocarcinoma (EAC) and squamous cell carcinoma (ESCC), respectively. ${ }^{1}$

However, high-aged patients and those with severe comorbidity are faced with considerable high postoperative morbidity and mortality. ${ }^{2}$ In these patients, who are medically unfit for surgery, definitive chemoradiotherapy (dCRT) would be a good alternative curative-intended treatment. ${ }^{3}$ Most studies in the past explored the usefulness of cisplatin-based regimen according to the RTOG 85-01 landmark study. Recent studies have shown more or less equal results of carboplatin/paclitaxel-based dCRT. In contrast with ESCC, data concerning the efficacy of dCRT in EAC are still lacking. Besides some recommendation, age and comorbidity are not clearly implemented in current treatment guideline of patients with EC. ${ }^{4,5}$

ASO Author Reflections is a brief invited commentary on the article, "Impact of age and comorbidity on choice and outcome of two different treatment options for patients with potentially curable esophageal cancer." Ann Surg Oncol. 2019;26:986-95. https://link. springer.com/article/10.1245/s10434-019-07181-6.

(C) The Author(s) 2019

First Received: 3 April 2019;

Published Online: 22 April 2019

J. T. M. Plukker, MD, PhD

e-mail: j.t.m.plukker@umcg.nl

\section{PRESENT}

Many elderly patients have multiple age-associated comorbidities, limiting the use of current combined treatment with either nCRT or dCRT. In our study age $\geq 75$ years and multiple comorbidities were associated with a higher probability for dCRT. Approximately $78 \%$ of these elderly patients were treated with dCRT. ${ }^{6}$ The strongest associations were found for the combination of hypertension plus diabetes and the combination of cardiovascular with pulmonary comorbidity. The results of this population-based study support the administration of dCRT in patients with ESCC having at least two comorbidities or being older than 75 years. This was seen particularly among those with cardiovascular diseases or previous malignancies, because their overall survival after dCRT was comparable to the overall survival for patients after nCRT plus surgery. However, in operable patients with locally advanced EAC, the use of nCRT plus surgery was associated with a better overall survival regardless of age, number, and type of pretreatment comorbidities.

\section{FUTURE}

In a selected group of elderly patients following dCRT, good results are reported with complete responses (58-68\%) and 2-year survival rates of 36-64\% against acceptable $\geq$ grade 3 toxicity (24-36\%). ${ }^{7}$ Several studies have stressed better results with dCRT in ESCC and the use of carboplatin/paclitaxel regimen with less toxicity and similar results compared with cisplatin-based dCRT. ${ }^{8,9}$

As functional rather than chronological older age is decisive for a proper treatment decision-making, comprehensive geriatric assessment is required in multidisciplinary tumor boards. Moreover, the increased risk of postoperative treatment-related morbidity and 
mortality in these patients is associated with the frailty index. Although there is no consensus on the definition of frailty and standardized cutoff points, comprehensive frailty testing facilitates an individualized preoperative risk assessment, while improving clinical outcome. ${ }^{10}$

Promising strategies are the use of biomarkers in combined chemoimmunotherapy as (neo)adjuvant, ${ }^{11}$ whereas improved outcome and less toxicity might be achieved by up-to-date radiation techniques, including intensity-modulated radiotherapy and proton therapy. ${ }^{12}$

DISCLOSURE The authors have no conflicts of interest to disclose.

OPEN ACCESS This article is distributed under the terms of the Creative Commons Attribution 4.0 International License (http://crea tivecommons.org/licenses/by/4.0/), which permits unrestricted use, distribution, and reproduction in any medium, provided you give appropriate credit to the original author(s) and the source, provide a link to the Creative Commons license, and indicate if changes were made.

\section{REFERENCES}

1. van Hagen $\mathrm{P}$, Hulshof MC, van Lanschot JJ, et al. Preoperative chemoradiotherapy for esophageal or junctional cancer. $N$ Engl $J$ Med. 2012;366(22):2074-84.

2. van Gestel YR, Lemmens VE, de Hingh IH, et al. Influence of comorbidity and age on 1-, 2-, and 3-month postoperative mortality rates in gastrointestinal cancer patients. Ann Surg Oncol. 2013;20(2):371-80.

3. Stahl M, Stuschke M, Lehmann N, et al. Chemoradiation with and without surgery in patients with locally advanced squamous cell carcinoma of the esophagus. $J$ Clin Oncol. 2005;23(10):2310-7.

4. Tougeron D, Scotté M, Hamidou, et al. Definitive chemoradiotherapy in patients with esophageal adenocarcinoma: an alternative to surgery? J Surg Oncol. 2012;105(8):761-6.

5. Kristjansson SR, Nesbakken A, Jordhøy MS, et al. Comprehensive geriatric assessment can predict complications in elderly patients after elective surgery for colorectal cancer: a prospective observational cohort study. Crit Rev Oncol Hematol. 2010;76(3):208-17.

6. Faiz Z, van Putten M, Verhoeven RHA, et al. Impact of age and comorbidity on choice and outcome of two different treatment options for patients with potentially curable esophageal cancer. Ann Surg Oncol. 2019;26:986-95. https://doi.org/10.1245/s1043 4-019-07181-6.

7. Tougeron D, Di Fiore F, Thureau S, et al. Safety and outcome of definitive chemoradiotherapy in elderly patients with oesophageal cancer. Br J Cancer. 2008;99(10):1586-92.

8. Best LM, Mughal M, Gurusamy KS. Nonsurgical versus surgical treatment for oesophageal cancer. Cochrane Database Syst Rev. 2016;3:CD011498

9. Honing J, Smit JK, Muijs CT, et al. A comparison of carboplatin and paclitaxel with cisplatinum and 5-fluorouracil in definitive chemoradiation in esophageal cancer patients. Ann Oncol. 2014;25(3):638-43.

10. Ethun CG, Bilen MA, Jani AB, et al. Frailty and cancer: implications for oncology surgery, medical oncology, and radiation oncology. CA Cancer J Clin. 2017;67(5):362-77.

11. Kelly RJ. Immunotherapy for esophageal and gastric cancer. $A m$ Soc Clin Oncol Educ Book. 2017;37:292-300.

12. Welsh J, Gomez D, Palmer MB, et al. Intensity-modulated proton therapy further reduces normal tissue exposure during definitive therapy for locally advanced distal esophageal tumours: a dosimetric study. Int J Radiat Oncol Biol Phys. 2011;81(5):1336-42.

Publisher's Note Springer Nature remains neutral with regard to jurisdictional claims in published maps and institutional affiliations. 